ein gedicht auf die königin Alis von England verfaßt haben, ïber die in der Joufroisstelle verhandelt wird.

Vielleicht empfiehlt es sich bei der beurteilung der hypothese teil 1 von teil $2 \mathrm{zu}$ trennen und nötigenfalls bei der kritik des letzteren die ergebnisse romanistischer erforschung des Joufrois abzuwarten.

Jedenfalls wäre schon bei annahme von teil 1 das gedicht MF. 3,7 definitiv aus der einheimischen lyrik ausgeschieden und für sehr frühe zeit auslăndischer einfluß nachgewiesen. Ferner wäre dem rätselraten über die königin von England durch die beziehung auf Alis, die zweite gemahlin Heinrichs I. ein dauerhaftes ende bereitet.

BRESLAU. KUDOLF PALGEN.

\title{
SALLIURE, SCHANTIURE, PARELIURE.
}

salliiure P 531,19 wird gewöhnlich mit 'spottrede' übersetzt und von einem ostfrz. salure, zum verbum saler = 'salzen' gehörig, abgeleitet (s. Maxeiner, Beitr. z. gesch. d. frz. wörter im mhd., Diss., Marburg 1897, s. 38, wo auch auf ein mlat. salitura $=\ddot{\alpha} \lambda \iota \omega \iota \iota$ [Ducange] hingewiesen wird). Fs wird auch all eine verbindung mit sale = 'schmutzig' gedacht. Beide etymologien müssen abgewiesen werden, schon deshalb, weil das grundwort im ersten fall keine bildliche bedeutung besitzt und im zweiten überhaupt nur erschlossen ist. Mir ist unerfindlich, weshalb man das wort nicht zu altfrz. saliier $=$ 'grüßen' stellen will. Wenn schon eine genau äquivalente form erschlossen werden soll, dann bin ich wohl berechtigt, auf die möglichkeit eines *salutura, frz. saluure hinzuweisen, was mit vereinigung der beiden $i i$ zu einem einzigen genau das Wolframsche wort ergibt. Aber ich möchte anch dieses verfahren ablehnen. Wolfram springt sehr frei mit den frz. wörtern um und es ist ihm wohl zuzutranen, dab er unter dem druck der reimnot aus einem verbum unter zuhilfenahme 
der verbreiteten fremdwortendung -iure sich wörter zu eigenem gebrauch bildet. Ich darf für diese erklärung in anspruch nehmen, daß sie allein einen unanfechtbaren sinn für die fragliche stelle 531, 19 ergibt: 'ihr spitziger grab erschien ihm so lieblich, daB er nicht bedachte, was sie sprach'. Man beachte, daB gerade an dieser stelle hintereinander mehrere gegensätze angewandt werden, wie nach meiner deutung die scharpfiu salliure ein oxymoron darstellt; so 26 ougen süeze unt sûr dem herzen bî.
sît vlust unt vinden an ir was
unt des siechin freade wol genas
daz frumt in zallen stunden
ledec nnt sêre gebunden.

Die stilistische spielerei geht von 531, 19 aus.

Singer greift in seiner abhandlung über Wolframs stil (Sitzungsberichte der kaiserl. akademie der wissenschaften in Wien, phil.-hist. kl. 180) s. 43 auf Maxeiners deutung des beinamens la schantiure für Kyot P 416, 21 zuriick (s. 65). Danach wäre $l$ der artikel und $a$ gehörte zum substantiv. Das ergebnis aschantiuve soll ein enchanteur wiedergeben; $a$ statt an oder en wird dialektisch sein oder nach Singer auf einem spontanen präfixwandel beruhen. Wie kommt aber Kyot, der dichter, zu dem beinamen 'der zauberer'? Maxeiner behilft sich indem er es offen läBt, ob enchanteur die auch belegte bedeutung von chanteur gehabt habe (was einen zur bloBen erklärung des artikels immerhin etwas umständlichen weg ergibt), während Singer gar von der 'zauberstadt' Toledo phantasiert. Ich glaube demgegenüber daran festhalten zu müssen, dab $l a$ der artikel ist und schantiure 'sänger' bedeutet. Wolfram selbst versteht darunter einen sänger, wie aus 416, 23 hervorgeht:

er ensunge und spraeche só

dês noch genuoge werdent frô;

sowie 28: swaz er en franzoys da von gesprach. Ich betrachte schantiure als eine selbständige bildung Wolframs aus chanter. Ich glaube übersetzen zu sollen: 'Kyot hieß jener sănger, dessen kunst so groß war, daß er mit seinem singen und sagen noch heute viele erfreut'. Wenn wir so la schantiure gewissermaßen emancipiert, ans einem beinamen zum subject des satzes erhoben haben, dann bekommt der ausdruck die 
rolle eines modernen fremdwortes, das den deutschen ausdruck zur erhöhung der spracheleganz vertreten soll. Wenn Wolfram das wort selbständig aus chanter nach dem muster der wörter wie aventiure gebildet hat, weshalb gibt er ihm dann nicht den richtigen artikel? Er gebraucht doch das sicher auch selbständig aus parler gebildete pareliuve mit dem männlichen, dagegen salliuve mit dem weiblichen artikel. Ich erkläre mir das so, dab er bei verwendung des dentschen artikels mit scharfem sprachgefühl die richtige form anwendet, bei preziöser verwendung des französischen artikels aber vor vermeintlich französischen wörtern mechanisch den artikel vorsetzt, den die endung erfordert. Er will zeigen, daB er französisch kann, daß er weiß, daß -ure eine weibliche endung ist. Übrigens konnte er sich dabei anf einige gelehrte ausdrücke stützen, die, obwohl sie männliche personen bezeichnen, doch als feminina gebraucht werden, weil die etymologische endung $e$ sie als feminina empfinden läßt. Chrétien gebraucht (Perceval ed. Baist 561) Jesu Crist la profete sainte. Ferner findet man ein weibliches patriarche, ermite. Wir finden also im französischen denselben vorgang: fremdwörter werden, aus grammatischen rücksichten, weil sie die endung $e$ aufweisen, mechanisch mit dem weiblichen artikel versehen, obwohl sie männliche personen bezeichnen. Das sprachgefühl versagt vor der grammatischen form. Genau dasselbe liegt bei Wolfram vor, nur $d a ß$ er die fremdwörter durch hinzufügung einer auf - $e$ ausgehenden endung an das fremde verbum sich erst selbst bildet. Er glaubt aber richtige französische wörter vor sich zu haben und verfährt also genau wie die Franzosen gegenïber ihren gelehrten eindringlingen wie ermite, profete usw. Schließlich wäre auf ein verwischen des unterschiedes zwischen $l e$ und $l a$ in manchen mundarten hinzuweisen.

BRESLAU.

RUDOLF PALGEN. 